\title{
1p31, 7q21 and 18q21 chromosomal aberrations and candidate genes in acquired vinblastine resistance of human cervical carcinoma $\mathrm{KB}$ cells
}

\author{
JIN WANG ${ }^{1,3}$, LAI-SHAN TAI ${ }^{2}$, CHI-HUNG TZANG ${ }^{1}$, WAN FONG FONG ${ }^{1}$, \\ XIN-YUAN GUAN ${ }^{2}$ and MENGSU YANG ${ }^{1}$ \\ ${ }^{1}$ Department of Biology and Chemistry, City University of Hong Kong, 83 Tat Chee Avenue, Kowloon; ${ }^{2}$ Department \\ of Clinical Oncology, Queen Mary Hospital, The University of Hong Kong, Hong Kong, P.R. China
}

Received January 25, 2008; Accepted March 3, 2008

\begin{abstract}
Vinblastine (VBL) is used to treat certain kinds of cancer including Hodgkin's lymphoma, lung cancer, breast cancer, testicular cancer and cervical carcinoma. However, the rapid development of resistance during therapy remains a major clinical challenge. In order to reverse cancer cell resistance, the goal of this study was to find differentially expressed genes and chromosomal alterations in multidrug resistant (MDR) KB-v1 cells, further to probe the relationship between drug resistance and differential genes, and chromosomal changes in MDR cancer cells. Comparative genomic hybridization (CGH) analysis of MDR KB-v1 and their parental KB-3-1 cells revealed chromosomal changes; microarray-based expression profiling was carried out by comparing the gene expressions of MDR KB-v1 cells and KB-3-1 cells. We have identified 3 chromosomal gains in regions of 1p31, 7q21 and 18q21 in MDR cells and 10 genes (CYR61, UGTREL7, MBD1, NARS, ATP5A1, ABCB1, ABCB4, PEG10, MCM7, SERPINE1) contained in these regions were also up-regulated in MDR KB-v1 cells. Forty-nine genes were down-regulated when KB-v1 cells were subjected to lower dose or depletion of the drug. We have confirmed some gene expression changes by reverse transcription-polymerase chain reaction and Northern blots. These are the first data describing the relationship of 1p31 and 18q21 chromosomal aberrations and candidate genes in acquired vinblastine-
\end{abstract}

Correspondence to: Dr Mengsu Yang, Department of Biology and Chemistry, City University of Hong Kong, 83 Tat Chee Avenue, Kowloon, Hong Kong, P.R. China

E-mail: bhmyang@cityu.edu.hk

Present address: ${ }^{3}$ Molecular and Clinical Nutrition Section, National Institute of Diabetes and Digestive and Kidney Diseases, National Institutes of Health, Bethesda, MD 20892, USA

Key words: multidrug resistance, $\mathrm{CGH}$, chromosomal aberration, microarray, $\mathrm{KB}$ cell resistance. This study also demonstrates that the combination of CGH and cDNA microarray is a very useful tool to detect drug resistant targets in cancer treatment.

\section{Introduction}

Drug resistance is the major obstacle to be overcome during the systemic therapy of cancer. The terms of drug resistance and sensitivity are relative conditions that must be defined with respect to some standard reference frames. Once a drug has achieved a critical threshold, it will interact with a range of cellular macromolecules. These genetic changes result in the development and progression of cancer and appear to be induced to multidrug resistance. Mechanisms implicated in cellular resistance include overexpression of the multidrug resistance gene (MDR1) (1), multidrug resistance-associated protein (MRP) (2); and anti-apoptosis, such as increasing tolerance of DNA damage and DNA repair (3). However, different cancer cells have their different cellular resistant mechanism.

Human cervical carcinoma KB (oral carcinoma) cells, used for selection of the multidrug resistant (MDR) cell lines, represent a subclone of human HeLa cells. These cells were chosen for the study of MDR because they are highly sensitive to most chemotherapeutic drugs. MDR derivatives of $\mathrm{KB}$ cells were obtained by selection with vinblastine, colchicine, or adriamycin, which is associated with multidrug resistance (4). KB-v1 cell is a derivation of the MDR KB cell lines. Its parent cell line was KB-3-1. KB-v1 cells were maintained with $1 \mu \mathrm{g} / \mathrm{ml}$ vinblastine for drug resistance. We have found that the phenotype of the highly resistant lines was unstable and most of the resistance was lost by growing the cells in the absence of the drugs for 3-6 weeks.

The mechanisms of drug resistance in cancer cells need to be thoroughly studied at the molecular level. Several lines of evidence have indicated that MDR in the highly resistant variants of $\mathrm{KB}$ cells was likely to be mediated by gene amplification. Comparative genomic hybridization (CGH) developed in 1992 has been utilized to identify DNA copy number abnormalities in various kind of cancers (5). In a typical CGH measurement, two genomes can be compared simultaneously, the total genomic DNA is isolated from test 
and reference cell populations. The metaphase chromosomes were used for the representation of the genome and the location of copy number variations between test and reference genomic DNA was mapped to the physical position on the chromosomes (6). DNA amplification is also an important mechanism that allows cancer cells to increase expression of drug resistant related genes (7). CGH copy number profiles may facilitate identification of important new drug resistant genes located at the hotpots of the chromosomal alterations.

cDNA microarrays technique is a high-capacity system, which was developed to monitor the expression of many genes in a single experiment $(8,9)$. cDNA microarray has been used to examine the development of drug resistance in cancer by comparing the gene expressions of MDR cancer cells and their parental cells (10-13). We have used statistical analysis of microarray data with Partek software. Partek Genomics Solution is a comprehensive suite of advanced statistics and interactive data visualization specifically designed to reliably extract biological signals from noise. It supports a complete workflow including convenient data access tools, identification and annotation of important drug resistant biomarkers. These analyses ultimately may enable us to use the signature expression profiles of drug resistance to predict response to drugs and to carry on chemotherapy or gene therapy.

In this study, we report the identification of genes associated with the vinblastine-resistant phenotype based on a different approach designed, advance technologies and software in MDR cells maintained with different doses of drug and comparing the expression patterns and copy number between MDR KB-v1 and its parental cell line.

\section{Materials and methods}

Cells. The KB cell line, KB-3-1 was purchased from the American Type Culture Collection. KB-v1 cell line is a derivation of the MDR KB cell lines, whose parent cell line was a KB subline designated KB-3-1. KB-v1 cells were obtained by selecting with vinblastine (VBL), which KB-3-1 was developed by selecting with vinblastine (starting at 0.2 $\mu \mathrm{g} / \mathrm{ml}$ and ending up with $1 \mu \mathrm{g} / \mathrm{ml}$ ). KB-3-1 and KB-v1 cells were cultured in DMEM media supplemented with $10 \%$ heat-inactivated fetal calf serum and antibiotics, penicillin and streptomycin.

Cytotoxicity assay. For the SRB (sulforhodamine B) assay standard procedures were used (14). KB cells were plated in 96-well plates $\left(10^{4}\right.$ cells/well) and grown overnight at $37^{\circ} \mathrm{C}$ in a $5 \% \mathrm{CO}_{2}$ incubator. Test compounds (vinblastine or doxorubicin) were then added to the wells to achieve a final concentration ranging from $10^{-6}$ to $10^{-4} \mathrm{M}$. Control wells were prepared by adding $100 \mu \mathrm{l}$ culture medium. The plates were incubated at $37^{\circ} \mathrm{C}$ in a $5 \% \mathrm{CO}_{2}$ incubator for $72 \mathrm{~h}$. After adding $50 \mu \mathrm{l}$ of $50 \%$ trichloroacetic acid (TCA) for $10 \mathrm{~min}$ at room temperature, the plates were then put at $4^{\circ} \mathrm{C}$ for $4 \mathrm{~h}$ and the supernate were removed, washed 5 times with $3 \mathrm{D}_{2} \mathrm{O}$. Then, $35 \mu 10.4 \%$ (wt/vol) SRB was added to each well for $30 \mathrm{~min}$. Unbound dye was removed by four washes with $1 \%$ acetic acid. The protein-bound dye was extracted with $10 \mathrm{mM}$ Tris base at a wavelength of $515 \mathrm{~nm}$. The $\mathrm{IC}_{50}$ was determined from the plots of $\%$ viability vs. dose of compound added.

Cell cycle analysis. To determine cell cycle distribution, $5 \times 10^{5} \mathrm{~KB}-3-1$ and KB-v1 cells were plated in 60-mm dishes, treated with $0.2 \mu \mathrm{g} / \mathrm{ml}$ of vinblastine. Cells were then collected by trypsinization, fixed in $95 \%$ ethanol, washed in $1 \%$ BSAPBS, resuspended in $1 \mu \mathrm{g} / \mathrm{ml}$ of RNase and $50 \mu \mathrm{g} / \mathrm{ml}$ of propidium iodide (PI), incubated for $30 \mathrm{~min}$ in the dark at $37^{\circ} \mathrm{C}$, and analyzed by flow cytometry using a FACSCalibur. The data were analyzed using the ModFit DNA analysis program.

$\mathrm{CGH}$. CGH was performed essentially as described previously $(5,15)$. The genomic DNA was prepared from KB cell lines, using DNA isolation Kit (Boehringer Mannheim Corp., IN, USA). DNA was labeled by nick translation using direct Spectrum green (test) and Spectrum red (reference) conjugated with dUTP (Vysis, Downers Grove, IL). Target metaphase spreads were prepared from PHA-stimulated peripheral blood lymphocytes from a healthy donor. Slides were dehydrated in 70,80 and $95 \%$ ethnol; denatured in $70 \%$ formamide/2X SSC at $70-72^{\circ} \mathrm{C}$ for $2 \mathrm{~min}$; and further dehydrated in ice-cold ethnol. For each hybridization, $1 \mu \mathrm{g}$ labeled test DNA, $1 \mu \mathrm{g}$ reference DNA and $12.5 \mu \mathrm{g}$ Cot-1 DNA were mixed and ethnol-precipitated. DNA was resuspended in $14 \mu \mathrm{l}$ hybridization mix containing $50 \%$ formamide, 2 X SSC and $10 \%$ dextran sulfate, denatured at $70^{\circ} \mathrm{C}$ for $5 \mathrm{~min}$ and applied to denatured metaphase spreads. Slides were incubated at $37^{\circ} \mathrm{C}$ in moist chamber for 2 days. Standard post-hybridization washes were performed. Slides were counterstained with DAPI and mounted with antifading solution (Vectashied; Vector, Burlingame, CA).

Digital image analysis. Digital image analysis was performed as previous described (15). CGH hybridizations were analyzed using a digital image analysis system containing a Zeiss Axioplan 2 microscope equipped with a Sensys cooled-charged device camera (Photometrics Ltd., Tucson, AZ, USA). Three images of each metaphase cell were captured using filter wheel-mounted, single band excitation Rhodamine, FITC and DAPI filters. The image analysis was carried out using the Quips CGH program (Vysis). Five metaphase cells were analyzed to generate fluorescence ratio profiles in each case. Interpretation of the profiles was performed according to the program guidelines. The thresholds used for the interpretation of gains and losses of a DNA sequence copy number was defined as a tumor/reference ratio 1.25 or 0.75 , respectively, with both the standard and the reverse hybridization methods. High-copy-number amplification of a chromosomal region was defined as tumor/reference or KB-v1/ KB-3-1 ratio 1.50 .

cDNA microarrays experiments. The cDNA microarrays consisted of a total of 9982 known genes and EST clones from Incyte Cloneset. PCR products from these clones were prepared and spotted on glass slide according to standard procedures (16). RNAs were extracted from the cells using TRIzol reagent (Life Technologies, Inc.), as specified by the manufacturer. Fluorescent-labeled cDNA with $\mathrm{Cy} 3$ or $\mathrm{Cy} 5$ 
Table I. Cytotoxicity studies on $\mathrm{KB}$ cells by SRB assay $\left(\mathrm{IC}_{50}\right)$.

\begin{tabular}{lcccc}
\hline & $\mathrm{KB}-3-1$ & \multicolumn{2}{c}{ MDR KB-v1 } \\
\cline { 2 - 3 } Drug & $\mathrm{IC}_{50}(\mu \mathrm{M})$ & & $\mathrm{IC}_{50}(\mu \mathrm{M})$ & Resistance index \\
\hline Vinblastine & $6.77 \times 10^{-4}$ & & $\geq 1.1$ & $\geq 1625$ \\
Doxorubicin & 0.03 & & $\geq 1$ & $\geq 33$
\end{tabular}

aResistance index, ratio between the $\mathrm{IC}_{50}$ value of MDR KB-v1 and parental KB-3-1 cells.

(Amersham Pharmacia) was synthesized from $100 \mu \mathrm{g}$ of totalRNA by oligo(dT)-primed polymerization using SuperScript II reverse transcriptase (Life Technologies, Inc.) as described. In each hybridization, we used the same reference RNA, which was extracted from KB-3-1, labeled with Cy3-dUTP and the test line KB-v1 with Cy5-dUTP. The two cDNA pools were mixed and applied to the array in a hybridization mixture containing $3.5 \mathrm{X} \mathrm{SSC}, 0.3 \%$ SDS and $10 \mu \mathrm{g}$ of yeast tRNA. Hybridization took place under a glass coverslip in a humidified $65^{\circ} \mathrm{C}$ hybridization chamber for $14-16 \mathrm{~h}$. The slides were washed, dried and scanned by using ScanArray 4000.

Microarray data analysis. Average signal intensity and local background measurements were obtained for each spot on the array by using Scanalyze software. Local background was subtracted from the value of each spot on the array. Spots were considered negative and were eliminated from any further analysis if the values for both channels were less than a threshold value, which was defined as one SD above average value of negative control spots on the array. The two channels were normalized with respect to the median values for the remaining set of the array. The $\mathrm{Cy} 5 / \mathrm{Cy} 3$ fluorescence ratios were calculated from the normalized values. Statistical analysis of gene expression microarray data was carried on by the software of Partek Genomics Solution.
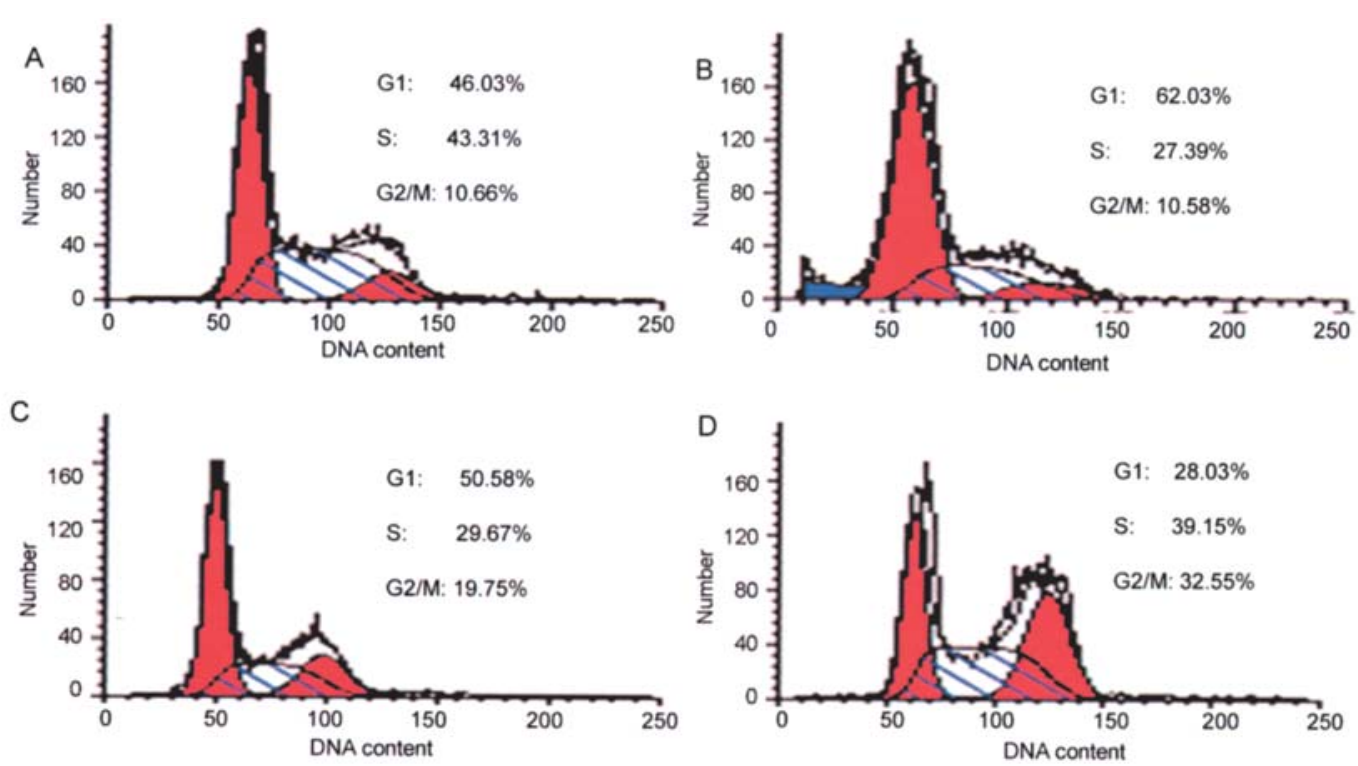

Figure 1. Effect of VBL on cellular DNA content. KB-3-1 and KB-v1 cells untreated and treated with VBL for 12 h. Cells were subjected to DNA content analysis by flow cytometry with PI staining. (A) KB-3-1 cells (untreated). (B) KB-v1 cells ( $1 \mu \mathrm{g} / \mathrm{ml} \mathrm{VBL})$. (C) KB-3-1 cells (0.2 $\mu \mathrm{g} / \mathrm{ml} \mathrm{VBL}, 30 \mathrm{~min})$. (D) KB-3-1 cells $(0.2 \mu \mathrm{g} / \mathrm{ml} \mathrm{VBL}, 12 \mathrm{~h})$.

Northern blotting. Total cellular RNA was isolated as described above, run on $1 \%$ agarose gel (15 $\mu \mathrm{g}$ per gel lane) containing 2.2 $\mathrm{M}$ formaldehyde, and transferred to a nitrocellulose membrane. Membrane was dried at room temperature, and RNA was cross-linked by UV irradiation in a Stratalinker (Stratagene). Hybridization was performed in ExpressHyb Hybridization buffer (Clontech) containing $1 \times 10^{6} \mathrm{cpm} / \mathrm{ml}$ of ${ }^{32} \mathrm{P}$-labeled cDNA probe at $65^{\circ} \mathrm{C}$ for $2 \mathrm{~h}$. Blots were washed in 2X SSC and $0.1 \%$ SDS for $20 \mathrm{~min}$, followed by a wash at $50^{\circ} \mathrm{C}$ in $0.2 \mathrm{X} \mathrm{SSC}$ and $0.1 \% \mathrm{SDS}$ for 20 min.

Semi-quantitative RT-PCR. The semi-quantitative analysis of mRNA expression levels of ABCB1, EST AI916259, SGK, ID1 in MDR KB-v1 maintained in $1 \mu \mathrm{g} / \mathrm{ml}$ VBL were evaluated by RT-PCR. It showed that the band intensity increased linearly with the amount of mRNA. B-actin was used to normalize the RNA quantity in each sample.

\section{Results}

Cytotoxicity studies on KB cells. Resistant KB cells (KB-v1) were derived by treating the cells with stepwise increasing concentrations of vinblastine, starting at $0.2 \mu \mathrm{g} / \mathrm{ml}$ and ending up at $1 \mu \mathrm{g} / \mathrm{ml}$ vinblastine. We tested the cytotoxicity of vinblastine and doxorubicin using SRB assay in highly multidrug-resistant KB-v1 cells, as well as in the drug-sensitive parental KB-3-1 cells. KB-v1 cells proved to be highly resistant to vinblastine (VBL) and doxorubicin (Dox) at the lethal dose $\left(\mathrm{IC}_{50}\right)$ values of $>1.1$ and $1 \mu \mathrm{M}$, respectively (Table I). The flow cytometry assay provides information regarding cell cycle based on analysis of their DNA content. The DNA content of vinblastine-treated KB-3-1 cell and MDR KB-v1 was examined by propidium iodide staining and flow cytometry. At $12 \mathrm{~h}$ post-treatment with $0.2 \mu \mathrm{g} / \mathrm{ml}$ of vinblastine, KB-3-1 cells were arrested predominately at G2/M phase of the cell cycle and G1 phase was apparently decreased (Fig. 1). The result indicated that KB-3-1 arrested 
B
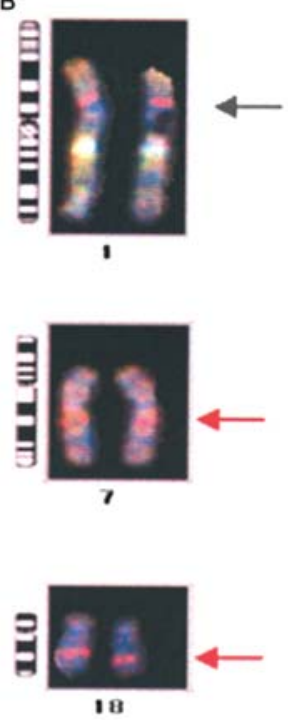
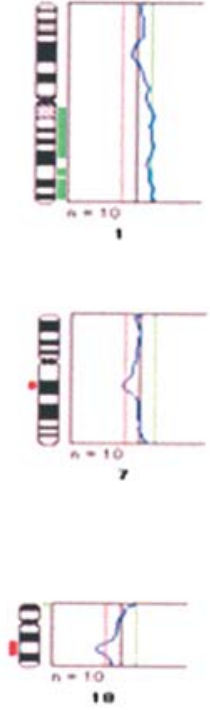

A
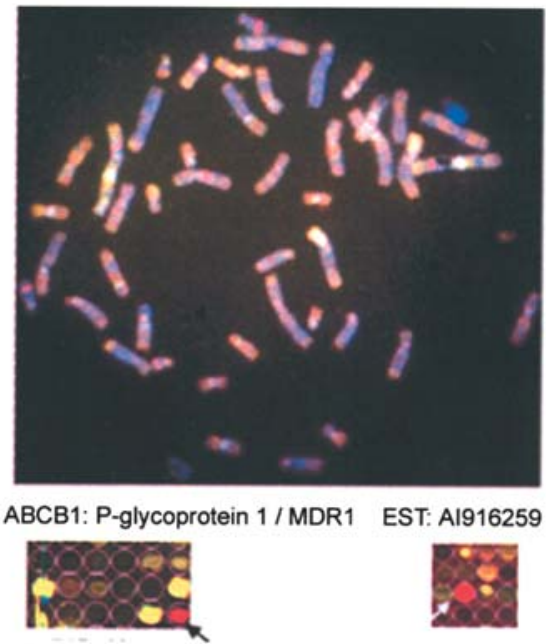

ABCB4: P-glycoprotein 3/ MDR3

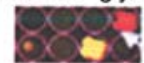

Figure 2. CGH and microarray for KB cell lines. (A) A representative image of CGH: MDR KB-v1 to KB-3-1 [KB-v1 labeled (spectrum red)/KB-3-1 labelled (spectrum green)]. (B) CGH analysis displays MDR KB-v1 cells have 3 chromosomal gains (1p31-1p22, 7q21 and 18q21) compared with its parental cell line (KB-3-1). (C) Microarray image of MDR1 genes. (KB-v1 labeled Cy5-dUTP/KB-3-1 labeled Cy3-dUTP; red spots showed MDR1 genes were overexpressed in MDR KB-v1 cells).

at $\mathrm{G} 2 / \mathrm{M}$ in response to vinblastine, but MDR KB-v1 did not arrest at $\mathrm{G} 2 / \mathrm{M}$ maintained in $1 \mu \mathrm{g} / \mathrm{ml} \mathrm{VBL}$. These results show that MDR KB-v1 is more resistant to vinblastine than its parental cell line KB-3-1.

CGH studies on chromosomal gains, loss and amplifications. Compared to normal reference, 7 and 13 genetic changes were found in KB-3-1, MDR KB-v1, respectively, including 4 losses and 3 gains in KB-3-1, 3 losses and 10 gains in MDR KB-v1. Fig. 2 and Table II demonstrate that some genetic imbalances are present in KB-3-1 and MDR KB-v1. We found that in chromosomal regions 1q12-1q21, 5p13-5p15, $5 q 32-5 q 34$, both MDR KB-v1 and its parental KB-3-1 cells showed chromosomal gains, whereas at 9p11, 9q12-9q13, Y chromosome, mutual losses of genetic material were detected in the two KB cell lines by CGH. However, 1p31-1p22, 7q21, 17p13, 17q24, 18q21, Xp22, Xq27 showed chromosomal gains only in MDR KB-v1 and 15p13-15p12 showed chromosomal losses only in KB-3-1. In further studies, 6 genetic changes were also found in MDR KB-v1 cell line, including 3 losses (1q12-1q21, 9q12-9q13 and Y chromosome) and 3 gains (1p31-1p22, 7q21 and 18q21) compared with its parental KB-3-1 cell line. One example of $\mathrm{CGH}$ ratio profiles is shown in Fig. 2.

Gene expression profiling in $\mathrm{KB}$ resistant cells and $\mathrm{CGH}$ analysis is consistent with gene expression profiles. Hybridization results of microarrays with Cy3-labeled cDNA probe from KB-3-1 cells and Cy5-labeled MDR KB-v1 demonstrated that, $\sim 11.44 \%$ of the cDNAs exhibit more than a 1.5-fold expression level change. It is remarkable that drug transport, cell survival, cytoskeleton, tumor associated antigen, signal transduction and transcription, and the regulatory network of lipid metabolism play a role in acquired resistance to vinblastine (Table III). CGH with genomic DNA prepared from MDR KB-v1 as probe successfully identified genomic gains and/or losses in chromosomal regions coding putative genes associated with multidrug resistance. In the 3 chromosomal gains, 10 genes such as CYR61, UGTREL7, MBD1, NARS, ATP5A1, ABCB1, ABCB4, PEG10, MCM7, SERPINE1 were up-regulated in MDR KB-v1 cells using cDNA microarray analysis (Table IV). These genes included various members of families of ABC transporters, signal transduction, cytoskeleton proteins and metabolism.

Drug-resistance related genes were differentially expressed depending on drug concentration. Results of analysis of variance (ANOVA) by Partek Genomics Solution showed that the gene expression profiles of MDR KB-v1 were significantly different among three drug concentrations $(0$, 0.2 and $1 \mu \mathrm{g} / \mathrm{ml} \mathrm{VBL})$. By comparison of gene expression profiles in the drug-resistant and parental cells and at a normal cut-off value $>1.5$-fold, changes in the transcription levels were identified, 1467 genes/ESTs were differently expressed in MDR KB-v1 cells maintained in $1 \mu \mathrm{g} / \mathrm{ml} \mathrm{VBL}$, compared to its parental KB-3-1 cell line. We have also found that 379 genes/ESTs were differently expressed in the three drug concentrations of VBL in MDR KB-v1 cells (Fig. 3). Genes related to drug resistance were downregulated in the present of low drug concentration or in the absence of drug. Table III shows that many genes related in drug resistance in MDR KB-v1 were down-regulated when the KB-v1 is absent of VBL compared to in 1 or $0.2 \mu \mathrm{g} / \mathrm{ml}$ $\mathrm{VBL}$. Those genes were involved in $\mathrm{ABC}$ transporters (ABCB1, ABCA3 and ABCB2), signal transduction (SGK, STK12, STK15, SH3BP5, G3BP, PABPC4 and GEMIN4), inhibition of apoptosis (CRMP1, DAD1, DDB2, ID1 and UGT2B7), and lipid metabolism (ACAT1, LRP8 and HDLBP). Additional genes were keratin genes, melanoma antigen family and proteasome subunits. 
Table II. Chromosomal target regions and putative genes in multidrug resistant KB-v1 and its parental cell line.

\begin{tabular}{|c|c|c|}
\hline & $\begin{array}{l}\text { Chromosomal } \\
\text { target regions }\end{array}$ & Putative target genes \\
\hline & & $\begin{array}{l}\text { TAGLN2 (1q21-q25), EFNA1 (1q21-q22), FDPS (1q21.2), ENSA (1q21.1), } \\
\text { FLJ10687 (1q21.1), ILF2 (1q21.1), SH2D2A (1q21), PMF1 (1q12), TXNIP (1q12), }\end{array}$ \\
\hline \multirow[t]{8}{*}{ KB-3-1/normal } & 1q12-1q21 (gain) & RBM8A (1q12) \\
\hline & 5p13-5p15 (gain) & DAP (5p15.2), ENDOFIN (5p15.2-q14.3) \\
\hline & & H2AFY (5q31.3-q32), SLC6A7 (5q31-q32), ATOX1 (5q32), TTC1 (5q32-q33.2), \\
\hline & $5 q 32-5 q 34$ (gain) & $\mathrm{G} 3 \mathrm{BP}(5 \mathrm{q} 33.1)$ \\
\hline & 9p11 (lost) & ND \\
\hline & 9q12-q13 (lost) & ND \\
\hline & $15 \mathrm{p} 13-15 \mathrm{p} 12$ (lost) & ND \\
\hline & Y chromosome (lost) & RPS4Y (Yp11.3), EIF1AY (Yq11.223) \\
\hline \multirow[t]{19}{*}{ KB-v1/normal } & 1p31-1p22 (gain) & CTBS (1p22), GTF2B (1p22-p21), CYR61 (1p31-p22) \\
\hline & & TAGLN2 (1q21-q25), EFNA1 (1q21-q22), FDPS (1q21.2), ENSA (1q21.1), \\
\hline & & FLJ10687 (1q21.1), ILF2 (1q21.1), SH2D2A (1q21), PMF1 (1q12), TXNIP (1q12), \\
\hline & 1q12-1q21 (gain) & RBM8A (1q12) \\
\hline & 5p13-5p15 (gain) & $\operatorname{DAP}(5 \mathrm{p} 15.2)$, ENDOFIN (5p15.2-q14.3) \\
\hline & & H2AFY (5q31.3-q32), SLC6A7 (5q31-q32), ATOX1 (5q32), TTC1 (5q32-q33.2), \\
\hline & $5 q 32-5 q 34$ (gain) & G3BP $(5 q 33.1)$ \\
\hline & & ABCB1 (7q21.1), ABCB4 (7q21.1), ESTAI916259 (7q21.1), PEG10 (7q21), \\
\hline & 7q21 (gain) & SERPINE1 (7q21.3-q22), MCM7 (7q21.3-q22.1) \\
\hline & & $\begin{array}{l}\text { MYO1C (17p13), GEMIN4 (17p13), EIF4A1 (17p13), PSMB6 (17p13), ITGAE } \\
\text { (17p13), POLR2A (17p13.1), STK12 (17p13.1), PMI (17p13.1), HSA272196 }\end{array}$ \\
\hline & 17 p13 (gain) & (17p13.2), SPAG7 (17p13.3), ALOX15 (17p13.3), PAFAH1B1 (17p13.3) \\
\hline & 17q24 (gain) & FALZ (17q24), FLJ21347 (17q24.1) \\
\hline & & BCL2 (18q21), MBD1 (18q21), NARS (18q21.2-q21.3), ATP5AI (18q12-q21), \\
\hline & 18q21 (gain) & MAPK4 (18q12-q21) \\
\hline & Xp22 (gain) & ND \\
\hline & Xq27 (gain) & ND \\
\hline & 9p11 (lost) & ND \\
\hline & 9q12-q13 (lost) & ND \\
\hline & Y chromosome (lost) & RPS4Y (Yp11.3), EIF1AY (Yq11.223) \\
\hline \multirow[t]{9}{*}{ KB-v1/KB-3-1 } & 1p31-1p22 (gain) & CTBS (1p22), GTF2B (1p22-p21), CYR61 (1p31-p22) \\
\hline & & ABCB1 (7q21.1), ABCB4 (7q21.1), SRI (7q21.1), ESTAI916259 (7q21.1), PEG10 \\
\hline & 7q21 (gain) & (7q21), SERPINE1 (7q21.3-q22), MCM7 (7q21.3-q22.1) \\
\hline & & BCL2 (18q21), MBD1 (18q21), NARS (18q21.2-q21.3), ATP5A1 (18q12-q21), \\
\hline & 18q21 (gain) & MAPK4 (18q12-q21) \\
\hline & & $\begin{array}{l}\text { TAGLN2 (1q21-q25), EFNA1 (1q21-q22), FDPS (1q21.2), ENSA (1q21.1), } \\
\text { FLJ10687 (1q21.1), ILF2 (1q21.1), SH2D2A (1q21), PMF1 (1q12), TXNIP (1q12), }\end{array}$ \\
\hline & 1q12-q21 (lost) & RBM8A (1q12) \\
\hline & 9q12-9q13 (lost) & ND \\
\hline & Y chromosome (lost) & RPS4Y (Yp11.3), EIF1AY (Yq11.223) \\
\hline
\end{tabular}

Northern blots and semi-quantitative RT-PCR for verification of the array hybridization data. Northern blot analysis of BCL2L1, PTEN, CLU, CGA, ENO3, KRT7 and B-actin was performed on RNA prepared from KB-3-1 cells and KB-v1 cells, which were maintained in $0.2 \mu \mathrm{g} / \mathrm{ml} \mathrm{VBL}$.
These results demonstrated that BCL2L1, PTEN, CGA, CLU, ENO3 and KRT7 were overexpressed in KB-v1 compared to 3 -actin as control (Fig. 4A).

The semi-quantitative analysis of mRNA expression levels of ABCB1, EST AI916259, SGK, ID1 in MDR KB-v1 
Table III. The part of differently expressed genes detected by DNA microarray analysis.

\begin{tabular}{|c|c|c|c|c|c|}
\hline Genes/ESTs & No drug & $\begin{array}{c}0.2 \mu \mathrm{g} / \mathrm{ml} \\
\mathrm{VBL}\end{array}$ & $\begin{array}{c}1 \mu \mathrm{g} / \mathrm{ml} \\
\mathrm{VBL}\end{array}$ & $\begin{array}{l}\text { Gene } \\
\text { name }\end{array}$ & $\begin{array}{c}\text { Gene } \\
\text { Bank no. }\end{array}$ \\
\hline \multicolumn{6}{|l|}{ Drug transport } \\
\hline P-glycoprotein $1 /$ multiple drug resistance 1 & 1.153 & 1.370 & 4.531 & $\mathrm{ABCB} 1$ & NM000927 \\
\hline ESTs & 6.737 & 8.113 & 31.36 & ABCB1 & AI916259 \\
\hline P-glycoprotein 3/multiple drug resistance 3 & 2.773 & 2.267 & 10.66 & ABCB4 & X06181 \\
\hline ATP-binding cassette 3 & -2.25 & -1.30 & 1.69 & $\mathrm{ABCA} 3$ & NM_001089 \\
\hline Transporter 1, ABC (ATP binding cassette) & -1.35 & -1.25 & 1.603 & TAP1 & NM_000593 \\
\hline ATP-binding cassette 50 & -1.49 & 1.318 & 1.463 & ABCF1 & NM_001090 \\
\hline ATP-binding cassette, sub-family B & 1.550 & 1.629 & 1.253 & ABCB6 & AI653711 \\
\hline Solute carrier family 6 & 2.584 & 3.04 & 4.551 & SLC6A7 & AI986397 \\
\hline Solute carrier family 4 , anion exchanger & 1.223 & -1.53 & -2.31 & SLC4A2 & NM_000340 \\
\hline Solute carrier family 38 , member 1 & -4.083 & -1.76 & -2.83 & SLC38A1 & BF348345 \\
\hline \multicolumn{6}{|l|}{ Cell survival } \\
\hline Defender against cell death 1 & 4.512 & 5.31 & 3.86 & DAD1 & AV714320 \\
\hline Collapsin response mediator protein 1 & 1.452 & 1.372 & 3.623 & CRMP1 & BF343909 \\
\hline Clusterin & 3.571 & 5.439 & 3.506 & CLU & BF525595 \\
\hline Inhibitor of DNA binding 1 & -1.42 & 2.927 & 4.268 & ID1 & AL117381 \\
\hline UDP glycosyltransferase 2 family, polypeptide B7 & -1.71 & 2.385 & 2.15 & UGT2B7 & BF689099 \\
\hline Damage-specific DNA binding protein $2(48 \mathrm{kDa})$ & 1.497 & 1.385 & 2.149 & DDB2 & NM_000107 \\
\hline Enolase $3,(\beta$, muscle $)$ & 1.094 & 2.448 & 1.503 & ENO3 & NM_001976 \\
\hline Inhibitor of growth family, member 1 & 1.666 & -5.297 & -2.275 & ING1 & AF181850 \\
\hline Tumor rejection antigen (gp96) 1 & 1.021 & -1.06 & -3.463 & TRA1 & AV655628 \\
\hline Thioredoxin interacting protein & -2.046 & -8.274 & -7.838 & TXNIP & AU139227 \\
\hline Heat shock protein 75 & -2.258 & -2.679 & -52.11 & TRAP1 & BE901723 \\
\hline Proteasome 26S subunit, non-ATPase, 11 & -1.55 & 2.611 & 1.405 & PSMD11 & AB003102 \\
\hline Proteasome 26S subunit, ATPase, 5 & 1.163 & 2.279 & 2.037 & PSMC5 & AI568351 \\
\hline Proteasome 26S subunit, non-ATPase, 3 & 1.318 & 2.786 & 1.982 & PSMD3 & NM_002809 \\
\hline Ubiquitin specific protease 11 & 1.071 & 1.744 & 1.904 & USP11 & BG392606 \\
\hline Ubiquinol-cytochrome c reductase subunit & -1.17 & 2.033 & 2.104 & UQCR & AW163002 \\
\hline \multicolumn{6}{|l|}{ Melanoma antigen } \\
\hline Melanoma antigen, family D, 2 & -1.31 & 2.279 & 2.672 & MAGED2 & BF969633 \\
\hline Melanoma antigen, family A, 12 & -1.18 & 2.888 & 2.582 & MAGEA12 & L18877 \\
\hline Melanoma antigen, family A, 2 & -1.72 & 2.218 & 2.396 & MAGEA2 & BG029985 \\
\hline Melanoma antigen, family A, 6 & -1.45 & 1.958 & 1.671 & MAGEA 6 & NM_005363 \\
\hline CD63 antigen (melanoma 1 antigen) & 1.175 & 1.464 & 1.944 & CD63 & BE907932 \\
\hline \multicolumn{6}{|l|}{ Cytoskeleton } \\
\hline Keratin, hair, basic, 3 & 1.950 & 2.737 & 5.992 & KRTHB3 & NM_002282 \\
\hline Keratin 8 & 2.055 & 1.782 & 2.999 & KRT 8 & B100080 \\
\hline Keratin 17 & 1.019 & 1.395 & 2.60 & KRT17 & AI521362 \\
\hline Keratin 7 & -2.21 & 2.273 & 2.51 & KRT7 & AA307373 \\
\hline Keratin 7 & -2.14 & 2.235 & 2.493 & KRT7 & BI094014 \\
\hline Tropomyosin 4 & -1.31 & -1.05 & 2.242 & TPM4 & BC002827 \\
\hline Crystallin, $\alpha \mathrm{B}$ & -1.51 & 1.109 & 2.552 & CRYAB & BF727296 \\
\hline Selenoprotein W, 1 & 1.117 & 1.519 & 2.815 & SEPW1 & BG476052 \\
\hline Lectin, galactoside-binding, soluble & 2.421 & 2.308 & 2.614 & LGALS3BP & L13210 \\
\hline Membrane protein of cholinergic synaptic vesicles & 1.150 & 2.262 & 3.193 & VATI & BG763127 \\
\hline \multicolumn{6}{|l|}{ Signal transduction and transcription } \\
\hline Glycoprotein hormones, $\alpha$ polypeptide & 5.221 & 5.293 & 5.247 & CGA & BG620346 \\
\hline
\end{tabular}


Table III. Continued.

\begin{tabular}{|c|c|c|c|c|c|}
\hline Genes/ESTs & No drug & $\begin{array}{c}0.2 \mu \mathrm{g} / \mathrm{ml} \\
\mathrm{VBL}\end{array}$ & $\begin{array}{c}1 \mu \mathrm{g} / \mathrm{ml} \\
\mathrm{VBL}\end{array}$ & $\begin{array}{l}\text { Gene } \\
\text { name }\end{array}$ & $\begin{array}{c}\text { Gene } \\
\text { Bank no. }\end{array}$ \\
\hline Serum/glucocorticoid regulated kinase & -1.22 & 3.636 & 4.705 & SGK & BG756781 \\
\hline Nuclear body protein Sp140 & 5.370 & 4.661 & 5.590 & Sp140 & NM_007237 \\
\hline Insulin-like growth factor binding protein 6 & 1.189 & 2.97 & 3.227 & IGFBP6 & BG326454 \\
\hline Adhesion regulating molecule 1 & -1.63 & -1.05 & 2.145 & ADRM1 & BF033463 \\
\hline Serine/threonine kinase 15 & -1.13 & 1.896 & 2.1 & STK15 & NM_003600 \\
\hline Serine/threonine kinase 12 & -1.10 & 1.989 & 1.568 & STK12 & BG616089 \\
\hline CD27-binding (Siva) protein & 1.108 & 1.559 & 3.086 & SIVA & AI267883 \\
\hline Inhibitor of DNA binding 1 & -1.42 & 2.927 & 4.268 & ID1 & AL117381 \\
\hline SH3-domain binding protein 5 & -1.56 & 1.437 & 6.296 & SH3BP5 & BG030766 \\
\hline Ras-GTPase-activating protein & -1.04 & 1.108 & 1.914 & G3BP & BG252290 \\
\hline $\mathrm{SH} 2$ domain protein $2 \mathrm{~A}$ & -2.398 & -3.46 & -4.652 & $\mathrm{SH} 2 \mathrm{D} 2 \mathrm{~A}$ & NM_003975 \\
\hline Poly(A) binding protein, cytoplasmic 4 & -2.60 & 2.468 & 1.906 & PABPC4 & BG392606 \\
\hline Poly(A) binding protein-interacting protein 1 & -4.386 & -1.56 & -2.206 & PAIP1 & AL548163 \\
\hline Activating transcription factor 1 & -2.406 & -1.814 & -2.843 & ATF1 & AI004969 \\
\hline Translocated promoter region & -1.08 & -1.587 & -3.28 & TPR & AI765790 \\
\hline CCAAT/enhancer binding protein $(\mathrm{C} / \mathrm{EBP})$ & -1.43 & -2.12 & -3.919 & CEBPB & W39546 \\
\hline Vascular endothelial growth factor & -1.667 & -12.343 & -2.288 & VEGF & AI085744 \\
\hline \multicolumn{6}{|l|}{ Lipid/cholesterol metabolism } \\
\hline High density lipoprotein binding protein & -1.93 & 1.772 & 2.758 & HDLBP & NM_005336 \\
\hline Phospholipid scramblase 3 & 1.155 & 2.77 & 2.296 & PLSCR3 & AF159442 \\
\hline Acetyl-Coenzyme A acetyltransferase 1 & 2.242 & 1.818 & 2.068 & ACAT1 & AI683154 \\
\hline 3-hydroxy-3methylglutaryl-Coenzyme A synthase1 & 1.340 & 2.928 & 2.816 & HMGCS1 & AW117731 \\
\hline Cholinergic receptor, nicotinic, $\alpha$ polypeptide 3 & -1.07 & -2.928 & -2.888 & CHRNA3 & AA927784 \\
\hline Low density lipoprotein receptor-related protein 8 & -1.758 & -1.962 & -2.895 & LRP8 & ВC006443 \\
\hline \multicolumn{6}{|l|}{ Other metabolic genes } \\
\hline UDP glycosyltransferase 2 family, polypeptide B7 & -1.71 & 2.385 & 2.15 & UGT2B7 & BF689099 \\
\hline Prolylcarboxypeptidase (angiotensinase C) & -1.32 & 1.386 & 2.135 & PRCP & AL540876 \\
\hline Protein geranylgeranyltransferase type I & -1.51 & -1.64 & 2.612 & PGGT1B & AA481712 \\
\hline Thiopurine S-methyltransferase & 1.202 & -1.35 & -3.212 & TPMT & AA974892 \\
\hline Deoxyribonuclease I & -1.07 & -1.37 & -2.143 & DNASE1 & AI802091 \\
\hline Deoxycytidine kinase & 1.241 & -2.951 & -2.27 & DCK & AI743955 \\
\hline Tyrosyl-tRNA synthetase & -1.776 & -1.653 & -2.887 & YARS & NM_003680 \\
\hline Dual specificity phosphatase 11 & 1.251 & -3.04 & -2.87 & DUSP11 & AI478561 \\
\hline Asparagine synthetase & -2.622 & -3.798 & -3.187 & ASNS & NM_001673 \\
\hline Dihydrofolate reductase & -1.41 & -3.436 & -3.376 & DHFR & NM_000791 \\
\hline Peptidylprolyl isomerase (cyclophilin)-like 3 & -1.02 & -1.29 & -3.529 & PPIL3 & AW971618 \\
\hline Selenophosphate synthetase 2 & -1.47 & -1.707 & -3.733 & SPS2 & AA604652 \\
\hline Dual-specificity tyrosine-(Y)-phosphorylation & 1.356 & -1.09 & -3.753 & DYRK1A & D86550 \\
\hline Procollagen-lysine, 2-oxoglutarate 5-dioxygenase & -1.996 & -1.27 & -3.821 & PLOD & AV711206 \\
\hline Alkaline phosphatase, placental (Regan isozyme) & -1.15 & -2.083 & -4.271 & ALPPL2 & BF807922 \\
\hline
\end{tabular}

The data are presented as the average (Avg) of three independent gene expression measurements expressed as a fraction of the total hybridization signal on each DNA microarray.

maintained in $1 \mu \mathrm{g} / \mathrm{ml}$ VBL were evaluated by RT-PCR. The result showed that the band intensity increased linearly with the amount of mRNA. B-actin was used to normalize the
RNA quantity in each sample (Fig. 4B). Northern blots and semi-quantitative RT-PCR analysis of highly expressed genes verified the array hybridization data. 
Table IV. CGH and cDNA microarray analysis of chromosomal target regions and up-regulated genes in MDR KB-v1 cells.

\begin{tabular}{|c|c|c|c|c|}
\hline $\begin{array}{l}\text { Gene } \\
\text { symbol }\end{array}$ & Chromosome & $\begin{array}{c}\mathrm{KB}-\mathrm{v} 1 \\
\text { to } 3-1\end{array}$ & Gene & $\begin{array}{c}\text { Accession } \\
\text { no. }\end{array}$ \\
\hline CYR61 & $1 \mathrm{p} 31-\mathrm{p} 22$ & 3.196 & Cysteine-rich, angiogenic inducer, 61 & Y12084 \\
\hline UGTREL7 & 1 p32-p31 & 3.149 & UDP-glucuronic acid/UDP-N-acetylgalactosamine dual transporter & D87449 \\
\hline MBD1 & $18 q 21$ & 1.520 & Methyl-CpG binding domain protein 1 & BE747161 \\
\hline NARS & $18 \mathrm{q} 21.2-\mathrm{q} 21.3$ & 4.047 & Asparaginyl-tRNA synthetase & BG706529 \\
\hline ATP5A1 & $18 \mathrm{q} 12-\mathrm{q} 21$ & 1.800 & ATP synthase, $\mathrm{H}^{+}$transporting, mitochondrial F1 complex & AU143446 \\
\hline $\mathrm{ABCB} 1$ & $7 q 21.1$ & 4.531 & ATP-binding cassette, sub-family B (MDR/TAP), member 1 & NM000927 \\
\hline $\mathrm{ABCB} 1$ & $7 q 21.1$ & 31.361 & ATP-binding cassette, sub-family B (MDR/TAP), member 1 & AI916259 \\
\hline ABCB4 & $7 q 21.1$ & 10.660 & ATP-binding cassette, sub-family B (MDR/TAP), member 4 & X06181 \\
\hline PEG10 & $7 q 21$ & 1.915 & Paternally expressed 10 & BG619874 \\
\hline MCM7 & $7 \mathrm{q} 21.3-\mathrm{q} 22.1$ & 1.959 & Minichromosome maintenance deficient (S. cerevisiae) 7 & BG683250 \\
\hline SERPINE1 & $7 q 21.3-q 22$ & 1.553 & Plasminogen activator inhibitor, type I & BE812315 \\
\hline
\end{tabular}

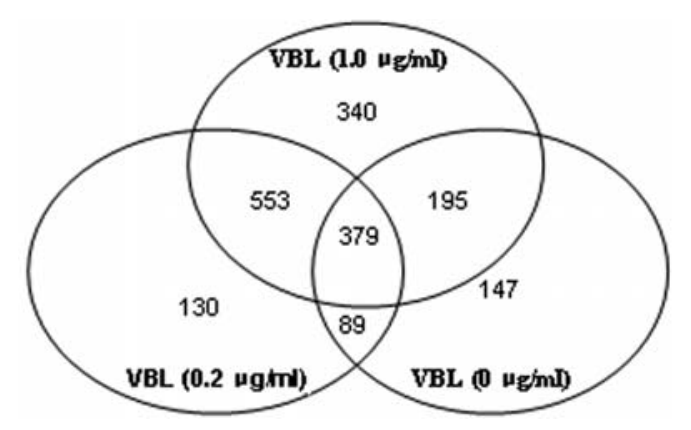

Figure 3. Differently expressed genes in MDR KB-v1 maintained in different drug concentration of VBL. Fold change values were calculated for all genes in MDR KB-v1 compared to its parental KB-3-1 cells. We identified 1467 genes/ESTs in the MDR KB-v1 maintained in $1 \mu \mathrm{g} / \mathrm{ml} \mathrm{VBL}$ that had a $>1.5$-fold difference in expression, and 379 genes/ESTs were commonly differentially expressed in MDR KB-v1 maintained in $0,0.2$ and $1 \mu \mathrm{g} / \mathrm{ml}$ VBL.

\section{Discussion}

Drug resistance occurs in cancer through various mechanisms. In this study, global expression profiles and genomic alterations in MDR KB-v1 cells were comprehensively analyzed using cDNA microarray and $\mathrm{CGH}$.

CGH has typically been applied to identify chromosomal aberrations in KB cancer cells DNA relative to normal genomic DNA. There were some common chromosomal alteration in both KB cancer cell lines. The regions 1q121q21, 5p13-5p15, 5q32-5q34 exhibited chromosomal gains in both cell clones. Common genetic losses were found in the regions 9p11,9q12-9q13 and Y chromosome. These common chromosomal aberrations in KB cells identified the genome changes in human cervical carcinoma.

CGH analysis of MDR KB-v1 cell line identified gains of 1p31-1p22, 7q21 and 18q21 and losses of 1q12-1q21,
A

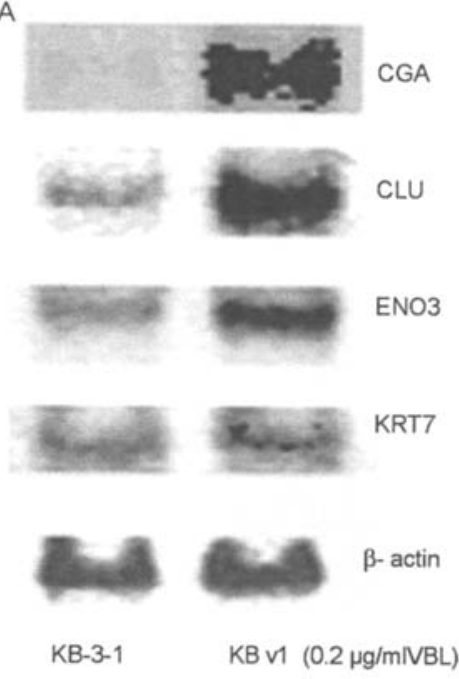

B
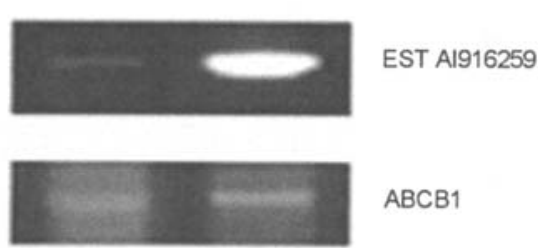

$A B C B 1$
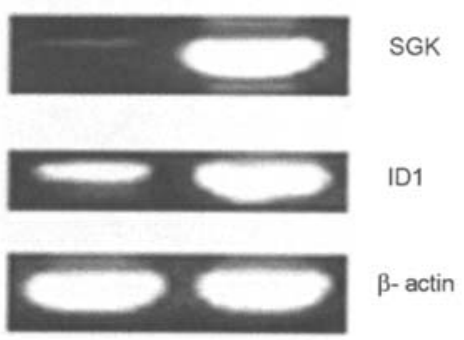

KB-3-1 KB $\quad \mathrm{K}(1.0 \mu \mathrm{g} / \mathrm{ml} \mathrm{VBL})$

Figure 4. (A) Northern blots and (B) semi-quantitative RT-PCR analysis of CGA, CLU, ENO3, KRT7, ABCB1, ID1, SGK and ESTAI916259, and B-actin was used to normalize the $R N A$ quantity in each sample. These results verify the array hybridization data. 
$9 q 12-9 q 13$ and $Y$ chromosome as the most prominent alterations by comparing with its parental cell line, KB-3-1 cells. It is well recognized that resistant cells with genetic alterations possessing a growth or survival advantage would lead to clonal expansion. Chromosomal 7q21 has also been reported in previous publications of MDR cancers (17-19). This is particularly helpful for MDR candidate evaluation. We determined correlations between chromosomal aberration and up- or down-regulation for 27 genes (Table II). The microarray analysis revealed that genes in the $7 \mathrm{q} 21.1$ chromosomal region, ABCB1, ABCB4, EST AI916259, were constitutively overexpressed in MDR KB-v1 cells. Other ABC transporters such as TAP1 (transporter 1), ABCA3, ABCB6 and ABCF1 were also up-regulated in MDR KB-v1 cells (Table III). These ATP binding cassette (ABC) transporters, localized in the cell membrane, caused drug resistance by extruding a variety of chemotherapeutic agents from the tumor cells. ABCB1, EST AI916259 and EST AA994037 were further verified highly expressed in MDR KB-v1 with semi-quantitative RT-PCR (Fig. 4). Computational analysis by genome mapping indicated that EST AA994037, EST AI916259 belongs to the 3'-untranslated regions (UTR) of ABCB1. P-glycoprotein (P-gp) coded for by mdr-1 (ABCB1) is an ABC (ATP-binding cassette) transporter, which hydrolyses ATP and extrudes cytotoxic drugs from mammalian cells.

P-gp association with the actin cytoskeleton was the key in conferring to human lymphoid cells a multidrug resistance phenotype (20). We found the tissue remodeling proteins such as KRTHB3, KRT7, KRT8, KRT17, TPM4, CRYAB, SEPW1, LGALS3BP and VATI were up-regulated in resistant cells (Table III). These showed that the intracellular vesicular transport of many compounds is partly controlled by cytoskeletal filaments.

The amplified region of $18 \mathrm{q} 21$ may contain more than one important gene, including BCL2 (18q21), MBD1 (18q21), NARS (18q21.2-q21.3), ATP5A1 (18q12-q21) and MAPK4 (18q12-q21). Up-regulation of $\mathrm{Bcl} 2$ protein expression might be one of the mechanisms of drug resistance in some cancer cells (21-23). ATP5A1 and ATP5C1 were also overexpressed in other resistant leukaemic cells (24). MBD1 was overexpressed in MDR KB-v1 cells. DNA methylation is the most common epigenetic alteration in tumor genomes and might result in transcriptional repression of tumor suppressor genes. Specific methylation patterns are involved in the development of therapy resistance of tumor cells (25).

The amplified region of $1 \mathrm{p} 31-1 \mathrm{p} 22$ contained CTBS (1p22), GTF2B (1p22-p21), and CYR61 (1p31-p22). CYR61 (CCN1) is an extracellular matrix-associated protein of the CCN family. CYR61 functions through integrin-mediated pathways to promote cell adhesion, migration, and proliferation, and can also promote cell survival and tubule formation in human umbilical vein endothelial cells and induce E2independence and antiestrogen-resistance $(26,27)$. These overexpressed genes helped identifying the drug resistance mechanism involving in many pathways such as changing cell membrane permeability, degradation, modification, transportation of drug and increasing drug efflux.

In our cDNA microarray, we also identified several repressed genes, which mapped to the regions of loss defined by CGH analysis of MDR KB-v1, compared to KB-3-1 cell line. These included TXNIP at 1q12 and SH2D2A (SH2 domain protein $2 \mathrm{~A}$ ) at $1 \mathrm{q} 21$. $\mathrm{SH} 2$ domain containing proteins play a key role in the process of intracellular transmission of signaling events initiated at the cell surface (28). TXNIP was identified as a negative regulator of thioredoxin (TXN). TXN is induced by a variety of oxidative stimuli, including UV irradiation, inflammatory cytokines and chemical carcinogens and has been shown to play crucial roles in the regulation of cellular responses such as gene expression, cell proliferation and apoptosis (29).

Besides chromosomal changes in MDR cells, some transcription factors (such as ATF1, BZAP45, TPR and CEBPB) and replication factor (RFC4) were repressed in MDR KB-v1 cells. Activating transcription factor 1 (ATF1), CREB, and the cyclic AMP (cAMP) response element modulatory protein (CREM), which constitute a subfamily of the basic leucine zipper transcription factors, activate gene expression by binding as homo- or heterodimers to the cAMP response element in regulatory regions of target genes. Those genes down-regulated in MDR KB-v1 may act as negative regulators of stress response mediating cell survival by altering drug sensitivity. Interesting, we also found that ID1 (inhibitor of DNA binding1) was up-regulated in MDR KB-v1 cells. ID family of helix-loop-helix proteins are generally considered to be negative regulators of similar proteins, mostly transcriptional activators (30).

In conclusion, $\mathrm{CGH}$ analysis of the KB-3-1 and KB-v1 cell lines revealed 6 genetic changes in MDR KB-v1 cell line, including 3 losses (1q12-1q21, 9q12-9q13 and Y chromosome) and 3 gains (1p31-1p22, 7q21 and 18q21) compared with its parental cell line KB-3-1. We determined correlations between chromosomal aberration and up- or down-regulation for 27 genes. These genes included various members of families of ABC transporters, cell survival, signal transduction, cytoskeleton proteins and metabolism, which are promising MDR candidates.

\section{Acknowledgements}

This study was supported by the City University of Hong Kong through a Strategic Research Grant (CityU Project No. 7001113).

\section{References}

1. Van der Bliek AM, Baas F, van der Velde-Koerts T, et al: Genes amplified and overexpressed in human multidrug-resistant cell lines. Cancer Res 48: 5927-5932, 1988.

2. Futscher BW, Abbaszadegan MR, Domann F and Dalton WS: Analysis of MRP mRNA in mitoxantrone-selected, multidrugresistant human tumor cells. Biochem Pharmacol 47: 1601-1606, 1994.

3. Middleton MR and Margison GP: Improvement of chemotherapy efficacy by inactivation of a DNA-repair pathway. Lancet Oncol 4: 37-44, 2003.

4. Bell SE, Quinn DM, Kellett GL and Warr JR: 2-Deoxy-Dglucose preferentially kills multidrug-resistant human KB carcinoma cell lines by apoptosis. Br J Cancer 78: 1464-1470, 1998.

5. Kallioniemi A, Kallioniemi OP, Piper J, et al: Detection and mapping of amplified DNA sequences in breast cancer by comparative genomic hybridization. Proc Natl Acad Sci USA 91: 2156-2160, 1994

6. Pinkel D and Albertson DG: Comparative genomic hybridization. Annu Rev Genomics Hum Genet 6: 331-354, 2005. 
7. Monni O, Barlund M, Mousses S, et al: Comprehensive copy number and gene expression profiling of the 17q23 amplicon in human breast cancer. Proc Natl Acad Sci USA 98: 5711-5716, 2001.

8. Schena M, Shalon D, Davis RW and Brown PO: Quantitative monitoring of gene expression patterns with a complementary DNA microarray. Science 270: 467-470, 1995.

9. Duggan DJ, Bittner M, Chen Y, Meltzer P and Trent JM: Expression profiling using cDNA microarrays. Nat Genet 21: 10-14, 1999.

10. Sakamoto M, Kondo A, Kawasaki K, et al: Analysis of gene expression profiles associated with cisplatin resistance in human ovarian cancer cell lines and tissues using cDNA microarray. Hum Cell 14: 305-315, 2001.

11. Kudoh K, Ramanna M, Ravatn R, et al: Monitoring the expression profiles of doxorubicin-induced and doxorubicinresistant cancer cells by cDNA microarray. Cancer Res 60: 4161-4166, 2000.

12. Komatani H, Kotani H, Hara Y, Nakagawa R, Matsumoto M, Arakawa $\mathrm{H}$ and Nishimura S: Identification of breast cancer resistant protein/mitoxantrone resistance/placenta-specific, ATP-binding cassette transporter as a transporter of NB-506 and $\mathrm{J}-107088$, topoisomerase I inhibitors with an indolocarbazole structure. Cancer Res 61: 2827-2832, 2001.

13. Levenson VV, Davidovich IA and Roninson IB: Pleiotropic resistance to DNA-interactive drugs is associated with increased expression of genes involved in DNA replication, repair and stress response. Cancer Res 60: 5027-5030, 2000.

14. Skehan P, Storeng R, Scudiero D, et al: New colorimetric cytotoxicity assay for anticancer-drug screening. J Natl Cancer Inst 82: 1107-1112, 1990

15. Guan XY, Fang Y, Sham JS, et al: Recurrent chromosome alterations in hepatocellular carcinoma detected by comparative genomic hybridization. Genes Chromosomes Cancer 29: 110-116, 2000.

16. Zhang Y, Song S, Fong CC, Tsang ZH, Yang Z and Yang M: cDNA microarray analysis of gene expression profiles in human fibroblast cells irradiated with red light. J Invest Dermatol 120: 849-857, 2003

17. Chen GK, Lacayo NJ, Duran GE, et al: Preferential expression of a mutant allele of the amplified MDR1 (ABCB1) gene in drugresistant variants of a human sarcoma. Genes Chromosomes Cancer 34: 372-383, 2002.

18. Takano M, Kudo K, Goto T, Yamamoto K, Kita T and Kikuchi Y: Analyses by comparative genomic hybridization of genes relating with cisplatin-resistance in ovarian cancer. Hum Cell 14: 267-271, 2001.
19. Tonnies H, Poland J, Sinha P and Lage H: Association of genomic imbalances with drug resistance and thermoresistance in human gastric carcinoma cells. Int J Cancer 103: 752-816, 2003.

20. Luciani F, Molinari A, Lozupone F, et al: P-glycoprotein-actin association through ERM family proteins: a role in P-glycoprotein function in human cells of lymphoid origin. Blood 99: 641-648, 2002.

21. Hong JH, Lee E, Hong J, Shin YJ and Ahn H: Antisense Bcl2 oligonucleotide in cisplatin-resistant bladder cancer cell lines. BJU Int 90: 113-117, 2002.

22. Frankel AE, Schuster MW and Jurcic JG: Novel therapeutics for chemotherapy-resistant acute myeloid leukaemia. Bio Drugs 15: 55-71, 2001

23. Kim PK, Mahidhara R and Seol DW: The role of caspase- 8 in resistance to cancer chemotherapy. Drug Resist Updat 4: 293-296, 2001.

24. Hofmann WK, De Vos S, Elashoff D, Gschaidmeier H, Hoelzer D, Koeffler HP and Ottmann OG: Relation between resistance of Philadelphia-chromosome-positive acute lymphoblastic leukaemia to the tyrosine kinase inhibitor STI571 and gene-expression profiles: a gene-expression study. Lancet 359: 481-486, 2002.

25. Schlegel J, Guneysu S and Mennel HD: Expression of the genes of methyl-binding domain proteins in human gliomas. Oncol Rep 9: 393-395, 2002

26. Leu SJ, Lam SC and Lau LF: Pro-angiogenic activities of CYR61 (CCN1) mediated through integrins alphavbeta3 and alpha6betal in human umbilical vein endothelial cells. J Biol Chem 277: 46248-46255, 2002.

27. Tsai MS, Bogart DF, Castaneda JM, Li P and Lupu R: Cyr61 promotes breast tumorigenesis and cancer progression. Oncogene 21: 8178-8185, 2002

28. Beattie J: SH2 domain protein interaction and possibilities for pharmacological intervention. Cell Signal 8: 75-86, 1996.

29. Nishinaka Y, Masutani H, Nakamura H and Yodoi J: Regulatory roles of thioredoxin in oxidative stress-induced cellular responses. Redox Rep 6: 289-295, 2001

30. Sun XH, Copeland NG, Jenkins NA and Baltimore D: Id proteins Id1 and Id2 selectively inhibit DNA binding by one class of helix-loop-helix proteins. Mol Cell Biol 11: 5603-5611, 1991. 